\title{
Paracrine control of tissue regeneration and cell proliferation by Caspase-3
}

\author{
$\mathrm{K}_{\text {Boland }}{ }^{1,2}$, L Flanagan ${ }^{1}$ and JHM Prehn ${ }^{*, 1}$
}

Executioner caspases such as Caspase-3 and Caspase-7 have long been recognised as the key proteases involved in cell demolition during apoptosis. Caspase activation also modulates signal transduction inside cells, through activation or inactivation of kinases, phosphatases and other signalling molecules. Interestingly, a series of recent studies have demonstrated that caspase activation may also influence signal transduction and gene expression changes in neighbouring cells that themselves did not activate caspases. This review describes the physiological relevance of paracrine Caspase-3 signalling for developmental processes, tissue homeostasis and tissue regeneration, and discusses the role of soluble factors and microparticles in mediating these paracrine activities. While non-cell autonomous control of tissue regeneration by Caspase-3 may represent an important process for maintaining tissue homeostasis, it may limit the efficiency of current cancer therapy by promoting cell proliferation in those cancer cells resistant to radio- or chemotherapy. We discuss recent evidence in support of such a role for Caspase-3, and discuss its therapeutic implication.

Cell Death and Disease (2013) 4, e725; doi:10.1038/cddis.2013.250; published online 11 July 2013

Subject Category: Cancer

Facts:

- Activation of the executioner Caspases-3 and -7 is responsible for cleavage of numerous cellular proteins, leading to the biochemical and morphological hallmarks of apoptosis.

- Recent work highlights the involvement of executioner caspases in mediating the release of paracrine factor(s), which stimulate proliferation and regeneration in neighbouring, non-apoptotic cells.

- Surviving cancer cells have been shown to be resistant to chemo- and radiotherapeutic insults and respond with accelerated repopulation and proliferation of tumour cells, effects that may be mediated in a Caspase-3-dependent manner.

\section{Open Questions:}

- How is Caspase-3 signalling in a paracrine manner from apoptosing cells stimulating signal transduction in nonapoptotic, neighbouring cells?

- Can specific inhibition of Caspase-3, or broad spectrum caspase inhibition in concert with chemotherapy lead to better patient responses and therapeutic outcomes?

- Is Caspase-3 a predictor of chemotherapy responsiveness?

Apoptosis is essential to maintain and support the normal life cycle, with central roles in embryonal development and, through the disposal of damaged or aged cells, in the regulation of adult tissue homeostasis. ${ }^{1,2}$ There is a fine balance between normal rates of apoptosis, excess apoptosis during degenerative conditions, and at the other extreme, failure of cells to undergo apoptosis contributing to hyperplasia, autoimmune disorders and cancer. ${ }^{3-8}$ Caspases are cysteine proteases that have critical roles in the orchestration of apoptosis, cleaving target proteins to execute cell death (Figure 1). The cell disassembly intrinsic to apoptosis is largely mediated by Caspase- 3 , which targets structural substrates including nuclear laminins, focal adhesion sites and cell-cell adherence junctions. ${ }^{9-14}$ The DNA fragmentation seen in apoptosis is also precipitated by Caspase-3, which cleaves Inhibitor of Caspase activated DNAase/DNA fragmentation factor 45 (ICAD/DFF45). ${ }^{15,16}$ This permits entry of Caspaseactivated DNAase (CAD) into the nucleus for DNA fragmentation leading to the characteristic ladder of DNA fragments. ${ }^{17}$

\footnotetext{
${ }^{1}$ Department of Physiology and Medical Physics, Centre for Systems Medicine, Royal College of Surgeons in Ireland, 123 Saint Stephen's Green, Dublin 2, Ireland and ${ }^{2}$ Department of Gastroenterology and Hepatology, Beaumont Hospital, Dublin 9, Ireland

*Corresponding author: JHM Prehn, Centre for Systems Medicine, Royal College of Surgeons in Ireland, 123 Saint Stephen's Green, Dublin 2, Ireland. Tel: + 3531402 2255; Fax: + 3531402 2447; E-mail: prehn@ @csi.ie

Keywords: caspases; apoptosis; cell proliferation; regeneration; stem cells; cancer

Abbreviations: AA, arachidonic acid; APAF1, apoptotic protease activating factor 1; ATP, Adenosine triphosphate; CAD, Caspase-activated DNAase; COX-2, Cyclooxygenase 2; DAMPs, danger-associated molecular patterns; DISC, death-inducing signalling complex; EKP, epidermal keratinocyte progenitor cell; ICAD/DFF45, Inhibitor of Caspase activated DNAase/DNA fragmentation factor 45; iPLA ${ }_{2}$, calcium-independent phospholipase $A_{2}$; LPC, lysophosphatidylcholine; MEF, mouse embryonic fibroblast; PARP, poly (ADP-ribose) polymerase; $\mathrm{PGE}_{2}$, prostaglandin $\mathrm{E}_{2} ; \mathrm{PSP} /$ reg, pancreatic stone protein/regenerating gene; RIP, receptor-interacting protein; Smac/DIABLO, second mitochondria-derived activator of caspase/Direct IAP-binding protein with low pl

Received 20.5.13; accepted 07.6.13; Edited by G Melino
} 


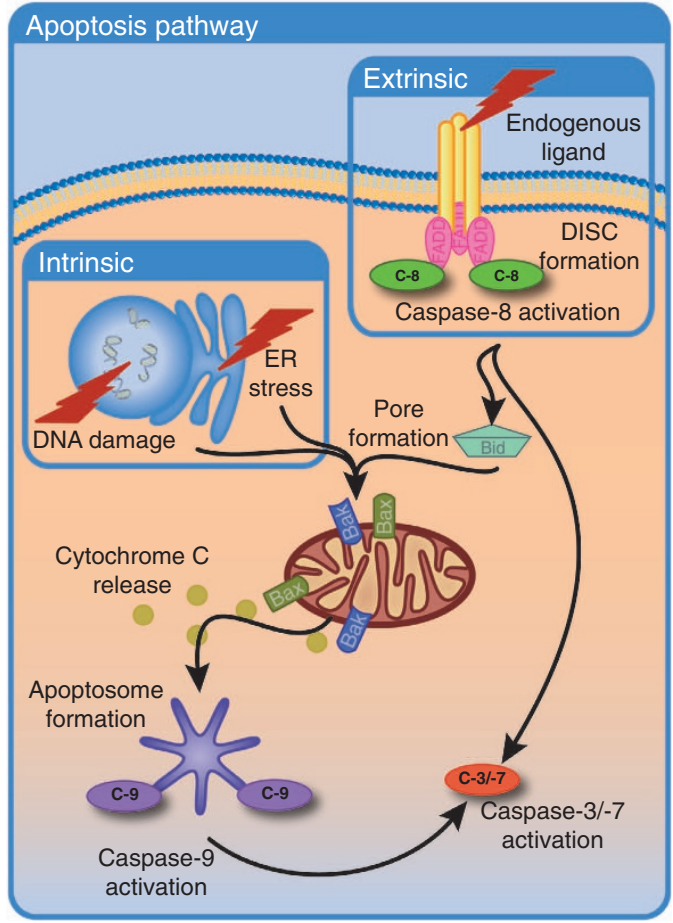

Figure 1 Caspase-3 activation via the intrinsic and extrinsic apoptotic pathways. Intrinsic apoptosis is induced by cellular stress, leading to the activation of the $\mathrm{Bcl}-2$ family of proteins. The BAK and BAX oligomers then promote pore formation in the outer mitochondrial membrane. Release of various intermembrane space proteins occurs. Cytochrome $\mathrm{C}$ binds to apoptotic protease activating factor 1 (APAF1), inducing the oligomerisation of APAF1 to form the apoptosome. The apoptosome recruits procaspase-9, leading to dimerisation and activation of Caspase-9. Caspase-9 activation stimulates the caspase cascade culminating in activation of executioner Caspases-3 and -7. These caspases are responsible for cleavage of numerous cellular proteins, leading to the biochemical and morphological hallmarks of apoptosis. The extrinsic apoptosis pathway is stimulated via ligand binding to their corresponding death receptors and recruitment of FADD to the death receptors occurs. FADD associates with procaspase-8/10 via its death effector domain to form the death-inducing signalling complex (DISC). DISC formation facilitates Caspase-8 cleavage and activation. The extrinsic pathway can then proceed via the type I signalling pathway or the type II signalling pathway. In type I signalling, Caspase-8 directly cleaves and activates Caspase-3 leading to cell death. In type II signalling, Caspase-8 instead cleaves BID to activate BAK and $B A X$. These proteins then induce pore formation in the mitochondria leading to activation of the caspase cascade and culminating in Caspase-3/-7 activation. C-9, Caspase-9; C-8, Caspase-8; C-7, Caspase-7; C-3, Caspase-3

Similarly to Caspase-3, Caspase-7 is also activated during the execution phase of apoptosis, and its functions partially overlap with Caspase-3 such that Caspase-3-deficient cells continue to execute apoptosis in the presence of Caspase-7. ${ }^{18}$ Indeed, deficiency in both Caspase-3 and Caspase- 7 is required to entirely prevent the activation of apoptosis. ${ }^{19}$ While Caspase-3 and Caspase-7 share many functions as executioner of apoptosis, there are also clear distinctions between these effectors both in the phenotypical appearance of Caspase-3 null and Caspase-7 null mice, and also at the molecular level. ${ }^{19}$ Generally, Caspase-3 demonstrates activity towards a wider range of substrates than Caspase- $7 .{ }^{20}$ However, redundancy between Caspase-3 and Caspase-7 is cell and stimulus dependent. ${ }^{21,22}$ One example where Caspase-3 likely has a more predominant role is the nervous system. Here, Caspase- 3 deficiency is sufficient to cause profound neuro-developmental defects. ${ }^{23}$

In the absence of Caspase-3 and Caspase-7, or in the presence of pharmacological pan-caspase inhibitors, cell death however also occurs, albeit in a more delayed manner and with different morphological features. During the intrinsic pathway, mitochondrial permeabilisation can activate caspase-independent cell death by adenosine triphosphate (ATP) depletion, activation of autophagy/mitophagy, or release of alternative pro-apoptotic factors from mitochondria. ${ }^{8}$ During the extrinsic pathway, Caspase- 3 is activated by Caspase-8. Caspase-8 also suppresses necroptosis via CYLD cleavage. ${ }^{24-26}$ Hence, administration of pan-caspase inhibitors can lead to necroptotic cell death during death receptor activation by enhancing the phosphorylation of receptor-interacting protein (RIP) 1 and RIP3. ${ }^{27}$ Even though cell death may not absolutely require Caspase-3 and Caspase-7, activation of these specific proteases is still of significant biological importance in the context of tissue homeostasis. Apoptosis and caspase activation during apoptosis have been shown to trigger the release of antiinflammatory cytokines and to suppress inflammatory responses, and hence play an important role in the control of immune responses. ${ }^{28-31}$ Investigation of the non-apoptotic functions of caspases has identified roles as negative regulators of the immune system, and their ability to attenuate inflammation is accomplished by affecting pro-inflammatory molecules, hence avoiding autoimmune responses ${ }^{32}$ (Figure 2). These pro-inflammatory danger-associated molecular patterns (DAMPs) are thought to be responsible for the mobilisation of the immune and inflammatory cascade in response to cellular necrosis. ${ }^{33}$ The immune system response to caspase-dependent and caspase-independent cell death is not identical and is responsible for the outcome of apoptosis in the former, and necrosis in caspase-independent cell death. It has been proposed that modifications of the inflammatory response by caspases are central to these contrasting outcomes, and inhibit autoimmunity induced by necrotic cells. ${ }^{32,34}$

It is now becoming increasingly evident that in addition to roles in immune system regulation, the activation of executioner caspases also has a direct role in tissue regeneration by stimulating signal transduction and cell proliferation in neighbouring, non-apoptotic cells. The fact that Caspase-3 not only functions to trigger the elimination of cells, but also has fundamental roles in signal transduction has been demonstrated in several previous studies. For example, Caspase-3 activates specific protein kinases and phosphatases during apoptosis. ${ }^{35,36}$ Caspase-3 has also been shown to activate Calcium-independent phospholipase $A_{2}$ ( $\left(P L A_{2}\right.$ ), generating lysophosphatidic acid and arachidonic acid (AA).$^{37}$ Interestingly, while lysophosphatidic acid may prevent apoptosis via blockage of poly (ADP-ribose) polymerase (PARP) cleavage and DNA fragmentation, AA has been shown to enhance cell migration in neighbouring, non-apoptotic cells. ${ }^{37}$ Lysophosphatidylcholine (LPC) generated by caspaseactivated $\mathrm{iPLA}_{2}$ sends out chemotactic 'eat me' signals to monocytic cells which then migrate to apoptotic cells, which are engulfed and removed. ${ }^{38}$ Caspases have also been suggested to have a role in non-apoptotic processes such as 


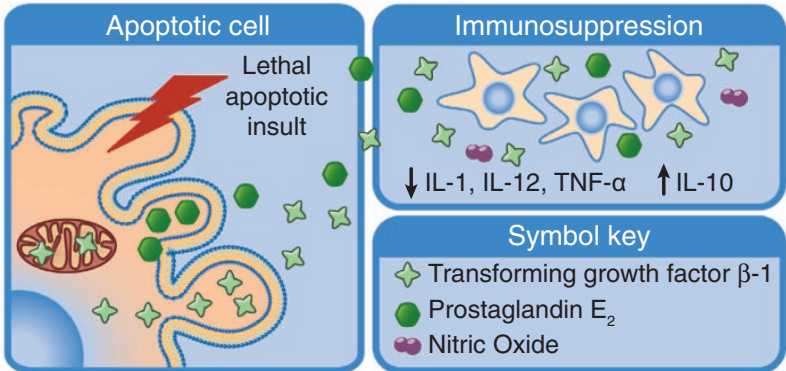

Figure 2 Paracrine signalling from apoptosing cells can regulate inflammatory responses. Apoptosis and caspase activation during apoptosis have been shown to play an important role in the control of immune responses by triggering the release of anti-inflammatory cytokines and suppressing inflammatory responses. Apoptotic cells exert their immunosuppressive effect by increasing secretion of the antiinflammatory cytokine IL-10 and decreasing secretion of pro-inflammatory cytokines IL-1, IL-12 and TNF- $\alpha$. TGF- $\beta-1$ secretion from apoptotic cells also enhances immune suppression via inhibition of pro-inflammatory cytokine production. IL, interleukin; TNF- $\alpha$, tumour necrosis factor $\alpha$; TGF- $\beta-1$, transforming growth factor $\beta-1$

T-cell proliferation, ${ }^{39}$ and in the course of cellular differentiation of osteoblasts, neural cells and skeletal muscle cell. ${ }^{40-42}$ Studies in $\mathrm{C} 3 \mathrm{H}$ mice demonstrate that Caspase-3 activation induces connective tissue growth factor, which encourages fibrogenesis in this model. ${ }^{43}$ Apoptotic signalling was also recently reported to promote myoblast fusion, an important step in the formation of mammalian skeletal muscle. Phosphatidylserine exposure seems to be the driving force behind this process in myoblasts. ${ }^{44}$

Caspase activation may even regulate complex physiological processes such as long-term potentiation and long-term depression. ${ }^{45,46}$ While many of these 'non-apoptotic' activities may be a consequence of 'physiological' or 'controlled' Caspase- 3 and -7 activation in cells, it is also possible that some of these activities result from paracrine signals that originate from apoptosing cells, but stimulate signal transduction in non-apoptotic, neighboring cells.

There is strong evidence from studies in model organisms in support of such a concept. Several studies investigated apoptosis as a trigger for tissue remodelling in response to tissue injury, identifying caspase activation as a key requirement for cell proliferation and recruitment of stem cells. In planaria, apoptotic waves have been shown to associate with tissue remodelling and regeneration. ${ }^{47}$ In Drosophila, mitotic figures are reoriented in response to cell death with documentation of apoptosis-induced compensatory proliferation. ${ }^{48}$ Apoptotic waves are also crucial to direct cellular regeneration in decapitated Hydra polyps. ${ }^{49}$ zVAD.fmk, a pan-caspase inhibitor, inhibits this wave of apoptosis, resulting in failure of head regeneration. Apoptotic cells were identified as the source of signals, directing cellular regeneration via secretion of Wnt3 and activation of the Wnt/ $\beta$-catenin pathway in non-apoptotic cells. ${ }^{49}$ The $\mathrm{Wnt} / \beta$-catenin pathway is critically involved in embryonic development as well as cell proliferation and regeneration. ${ }^{50,51}$ Once activated, this pathway leads to a buildup of $\beta$-catenin in the cytoplasm. Upon its translocation to the nucleus $\beta$-catenin activates transcription and upregulation of target genes implicated in cell cycle and proliferation. ${ }^{52,53}$ In the study by Chera et al.., ${ }^{49}$ in the decapitated group exposed to zVAD, Wnt levels remained low with no recorded nuclear translocation of $\beta$-catenin. The addition of Wnt3 to zVAD-treated Hydra induced $\beta$-catenin nuclear translocation and rescued head regeneration, validating the authors' hypothesis that caspases trigger tissue regeneration through actions on the $\mathrm{Wnt} / \beta$-catenin pathway.

Prostaglandin $\mathrm{E}_{2}\left(\mathrm{PGE}_{2}\right)$ production by apoptotic cells has been identified as a link between caspase activation and the activation of the $\mathrm{Wnt} / \beta$-catenin pathway in non-apoptotic cells. Caspase- 3 cleaves and activates $\mathrm{PLA}_{2}$, culminating in $\mathrm{PGE}_{2}$ production and secretion, and induction of $\beta$-catenin translocation and activation. ${ }^{37,54-56} \mathrm{Li}$ et al. ${ }^{57}$ described this pathway in the context of wound healing in mammalian cells, designated as the 'Phoenix Rising Pathway'. Preliminary work in this study examined the role of Caspase- 3 and Caspase-7 in promoting stem or progenitor cell proliferation by co-injecting epidermal keratinocyte progenitor cells (EKP) with wild type, Caspase-3-/ - or Caspase-7-/ lethally irradiated mouse embryonic fibroblasts (MEFs) into the hindlimbs of mice. EKP proliferation was greatest in the wild-type MEF model, with Caspase-3-I- and Caspase-7-I- models showing minimal proliferation. The Caspase-3- / - model exhibited the lowest rate of proliferation, indicating that this caspase may have a prominent role in this process. Li et al. also examined angiogenesis induced by wild-type or Caspase-3-/ - lethally irradiated MEFs using silicone cylinders containing the MEFs implanted into nude mice. After 2 weeks, irradiated wild-type MEFs had induced significant vascular growth in the host, while Caspase-3 - / MEFs induced minimal host vascular growth into the cylinder. Further in vivo work in this study revealed that mice deficient in either Caspase-3 or Caspase-7 exhibited reduced rates of tissue repair in dorsal skin wounds, with defects in liver regeneration following partial hepatectomy. The authors demonstrated that Caspase-3 and -7 were required to stimulate proliferation and regeneration via Caspase-3/-7dependent $\mathrm{PLA}_{2}$ activation, resulting in $\mathrm{AA}$ synthesis and subsequent $\mathrm{PGE}_{2}$ and $\mathrm{Wnt} / \beta$-catenin signalling. ${ }^{57}$ Paracrine signalling mediated by effector caspases has also been identified as a stimulus for cell proliferation and regeneration in beta cells. ${ }^{58}$ Insulin-secreting cells undergoing caspasedependent apoptosis have been identified to send out biochemical signals into their local environment that stimulate the differentiation or proliferation of neighbouring cells through the induction of regenerating (reg) genes. In these investigations, the supernatant of apoptosing beta cells was sufficient to induce expression of regenerating genes in non-apoptotic, naïve cells, and this effect was mediated by the caspasedependent shedding of microparticles from apoptosing cells, as gene induction in neighbouring cells was blocked either by caspase inhibition or by the removal of microparticles from the supernatant. Hence, paracrine signalling by Caspase-3 or Caspase-7 may represent an important process in the maintenance of tissue homeostasis, by stimulating cell proliferation, migration and possibly differentiation, thereby replacing injured cells ${ }^{59}$ (Figure 3 ).

While such paracrine functions of Caspase- 3 or Caspase-7 may be beneficial in the context of tissue injury and regeneration, they may limit the efficiency of current cancer therapy by promoting cell proliferation in the fraction of cancer 
cells resistant to radio- or chemotherapy. Most common chemotherapeutic agents induce apoptosis in cancer cells. The complex environment of cancer cells, coupled with a myriad of adaptive responses, mutated genes and altered metabolism means that not all cancer cells are equally sensitive to radio- or chemotherapy. ${ }^{60}$ The fractional kill hypothesis states that a defined chemotherapy concentration applied for a defined period of time will kill a constant fraction of cells in a population regardless of tumour size, relative to cell sensitivity to treatment. Of note, surviving cancer cells have been shown to respond to chemo- and radiotherapeutic insults with accelerated repopulation and proliferation of tumour cells ${ }^{61,62}$ (Figure 4). Indeed, increased proliferation rates have been reported to correlate with poor patient prognosis in many cancers. ${ }^{63,64}$ Coupled with cancer cell heterogeneity in responses is the presence of cancer stem cells, existing as a cell population within tumours. Cancer stem cells have been shown to be particularly resistant to

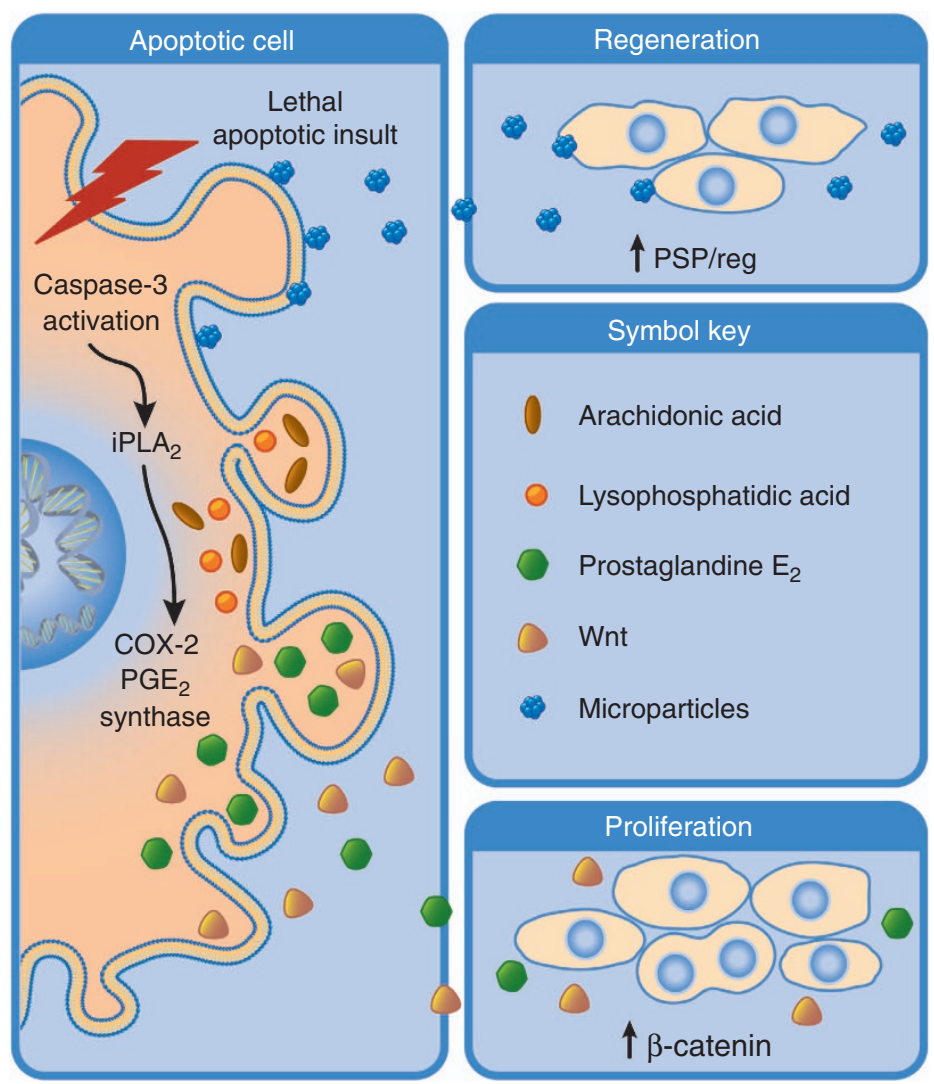

Figure 3 Paracrine signalling from apoptosing cells. Upon apoptosis induction, Caspase-3/-7 acts as an executioner caspase, responsible for cleavage of many cellular proteins, leading to the biochemical and morphological hallmarks of apoptosis, including oligonucleosomal DNA fragmentation. Recent work highlights new paracrine roles for Caspase-3 in stimulating proliferation and regeneration in neighbouring, non-apoptotic cells. Caspase-3 activation leads to iPLA 2 activation, and production of AA and LPA. AA stimulates $\mathrm{PGE}_{2}$ which, along with Wnt, activates $\beta$-catenin signalling in non-apoptotic cells, leading to increased cell proliferation and tissue regeneration. Shed microparticles from apoptosing cells may stimulate the induction of regenerating genes in neighbouring cells. iPLA, calcium-independent phospholipase $A_{2}$; COX-2, cyclooxygenase 2; LPA, lysophosphatidic acid; PSP/reg, pancreatic stone protein/regenerating gene; AA, arachidonic acid; $P \mathrm{GE}_{2}$, prostaglandin $\mathrm{E}_{2}$
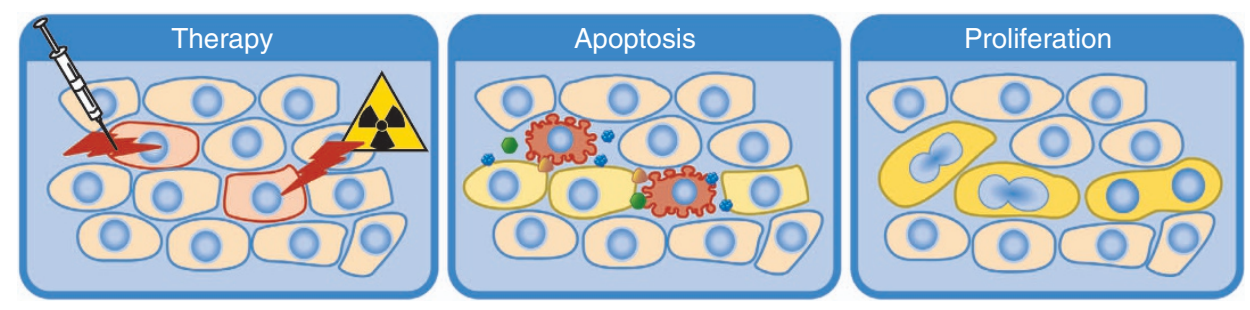

Figure 4 Paracrine Caspase-3/-7 signalling may limit the efficiency of cancer therapy. Common radio- or chemotherapies induce apoptosis in cancer cells (panel 1). As these cells die, they may trigger Caspase-3-/-7-dependent paracrine signalling (panel 2), thereby accelerating the repopulation of neighbouring tumour cells, and also increasing proliferation rates in more resistant cells that survive the chemo- or radiotherapeutic insult (panel 3). This signalling process may limit the efficacy of current cancer therapies 
chemotherapy, and have a unique capacity to initiate tumours, ${ }^{65,66}$ a capacity that may be stimulated by paracrine Caspase-3/-7 signalling. Paracrine signalling mediated by effector caspases, in particular Caspase-3, as a stimulus for tumour growth and proliferation has been recently demonstrated in the context of cancer therapy. ${ }^{54}$ In an in vivo model, labelled stem cells were implanted with and without irradiated MEFs representing apoptosing cells. The presence of apoptosing cells increased stem cell proliferation, as illustrated by the fact that tumour cell growth was markedly increased when the cells were implanted with irradiated MEFs, as opposed to implantation with live MEFs. However, implantation of Caspase-3-/ - irradiated MEFs did not stimulate proliferation, outlining a role for this specific caspase in the paracrine response leading to tissue regeneration. The authors also identified a crucial link between Caspase- 3 and $\beta$-catenin signalling. Importantly, Huang et al. ${ }^{54}$ pre-clinical study also addressed the clinical difficulties associated with appropriate management of patients with resistant cancers with relapse. In the cohort of patients studied, high levels of Caspase-3 correlated with high levels of tumour recurrence and also a shorter survival time. This contrasts starkly with the traditional view that Caspase- 3 and -7 activation is associated with successful therapy responses. It remains to be shown in future pre-clinical and clinical studies whether, and in which cancers, the activation of Caspase-3, and potentially also Caspase-7, may accelerate the repopulation of tumours, and may therefore represent important predictive biomarkers of therapy resistance and recurrence.

These recent findings may also have important therapeutic implications. Clearly, Caspase-3- and -7-dependent apoptosis is fundamental in chemotherapy-induced tumour regression, particularly in those tumours that are sensitive to effector caspase activation. Caspase-independent cell death pathways however also exist, and mitochondrial outer membrane permeabilisation rather than executioner caspase activation is considered as the 'point-of-no-return'. ${ }^{67,68}$ Inhibition of Caspase-3(-7) paracrine signalling may be an effective therapy particularly in chemoresistant tumours that show a less favourable patient outcome. Pan-caspase inhibition, rather than specific inhibition of Caspase-3/-7, may also be an interesting strategy, as it may activate alternative forms of cell death, such as necroptosis. ${ }^{26}$ However, pan-caspase inhibition in vivo may also increase the potential for nonspecific adverse effects. Antagonising downstream effectors of Caspase-3 paracrine signalling, such as $\mathrm{PGE}_{2}$ or components of the Wnt signalling pathway, may also represent a novel approach to halt, or at least impede, tumour cell repopulation following chemotherapy. These approaches could offer an interesting alternative and warrant further investigation. Specific targeting of Caspase-3 has already been suggested to inhibit cell proliferation in a lung cancer xenograft tumour model. A combination of radiotherapy and Caspase-3 inhibition significantly delayed the growth of tumours, and reduced tumour vascularisation when compared with controls. The treatment regime was also well tolerated. ${ }^{69}$ The recent work by Huang et al. ${ }^{54}$ also alludes to the potential of Caspase-3 inhibition as an approach to enhance patient response to radiotherapy. This group established a xenograft model using parental MCF-7 cells, which are naturally deficient in Caspase-3. Following radiation tumours in this model disappeared completely and did not re-grow during the course of the study. In contrast, in a xenograft model injected with MCF-7 cells transduced to express Caspase-3, tumours grew at a faster rate and were significantly more resistant to radiotherapy than the MCF-7 parental model, indicating that inactivity of Caspase-3 in tumour cells can render the tumour more susceptible to radiotherapy. Specific inhibition of Caspase-3 in concert with chemotherapy may be an interesting, novel approach for the treatment of those tumours characterised by fractional cell killing, resistance and relapse.

\section{Conflict of Interest}

The authors declare no conflict of interest.

Acknowledgements. We thank Ms. Jasmin Schmid for helpful discussions and assistance with figure design. Research in the laboratory is supported by grants from Science Foundation Ireland (08/IN.1/B1949) and the Health Research Board (TRA/2007/26; HRA_POR/2012/121).

1. Jacobson MD, Weil M, Raff MC. Programmed cell death in animal development. Cell 1997; 88: $347-354$

2. Oppenheim RW. Cell death during development of the nervous system. Annu Rev Neurosci 1991; 14: 453-501.

3. Carson DA, Ribeiro JM. Apoptosis and disease. Lancet 1993; 341: 1251-1254.

4. O'Reilly LA, Strasser A. Apoptosis and autoimmune disease. Inflamm Res 1999; 48: 5-21.

5. Lowe SW, Lin AW. Apoptosis in cancer. Carcinogenesis 2000; 21: 485-495.

6. Green DR. Means to An End: Apoptosis and Other Cell Death Mechanisms. Cold Spring Harbor Laboratory Press: Woodbury, NY, USA, 2012.

7. Johnstone RW, Frew AJ, Smyth MJ. The TRAIL apoptotic pathway in cancer onset, progression and therapy. Nat Rev Cancer 2008; 8: 782-798.

8. Kroemer G, Martin SJ. Caspase-independent cell death. Nat Med 2005; 11: 725-730.

9. Brancolini C, Lazarevic D, Rodriguez J, Schneider C. Dismantling cell-cell contacts during apoptosis is coupled to a caspase-dependent proteolytic cleavage of beta-catenin. $J$ Cell Biol 1997; 139: 759-771.

10. Kook S, Kim DH, Shim SR, Kim W, Chun JS, Song WK. Caspase-dependent cleavage of tensin induces disruption of actin cytoskeleton during apoptosis. Biochem Biophys Res Commun 2003; 303: 37-45.

11. Taylor RC, Cullen SP, Martin SJ. Apoptosis: controlled demolition at the cellular level. Nat Rev Mol Cell Biol 2008; 9: 231-241.

12. Thornberry NA, Lazebnik Y. Caspases: enemies within. Science 1998; 281: 1312-1316.

13. Kothakota S, Azuma T, Reinhard C, Klippel A, Tang J, Chu K et al. Caspase-3-generated fragment of gelsolin: effector of morphological change in apoptosis. Science 1997; 278: 294-298

14. Timmer JC, Salvesen GS. Caspase substrates. Cell Death Differ 2007; 14: 66-72.

15. Janicke RU, Sprengart ML, Wati MR, Porter AG. Caspase-3 is required for DNA fragmentation and morphological changes associated with apoptosis. J Biol Chem 1998; 273: 9357-9360.

16. Liu X, Zou H, Slaughter $C$, Wang X. DFF a heterodimeric protein that functions downstream of caspase-3 to trigger DNA fragmentation during apoptosis. Cell 1997; 89: 175-184.

17. Enari M, Sakahira H, Yokoyama H, Okawa K, Iwamatsu A, Nagata S. A caspase-activated DNase that degrades DNA during apoptosis, and its inhibitor ICAD. Nature 1998; 391: 43-50.

18. Zheng TS, Hunot S, Kuida K, Momoi T, Srinivasan A, Nicholson DW et al. Deficiency in caspase-9 or caspase-3 induces compensatory caspase activation. Nat Med 2000; 6 : 1241-1247.

19. Lakhani SA, Masud A, Kuida K, Porter GA, Booth CJ, Mehal WZ et al. Caspases 3 and 7 : key mediators of mitochondrial events of apoptosis. Science 2006; 311: 847-851.

20. Walsh JG, Cullen SP, Sheridan C, Lüthi AU, Gerner C, Martin SJ. Executioner caspase-3 and caspase-7 are functionally distinct proteases. Proc Natl Acad Sci 2008; 105: $12815-12819$

21. Woo M, Hakem R, Soengas MS, Duncan GS, Shahinian A, Kagi D et al. Essential contribution of caspase 3/CPP32 to apoptosis and its associated nuclear changes. Genes Dev 1998; 12: 806-819.

22. Wolf BB, Schuler M, Echeverri F, Green DR. Caspase-3 is the primary activator of apoptotic DNA fragmentation via DNA fragmentation factor-45/inhibitor of Caspaseactivated DNase inactivation. J Biol Chem 1999; 274: 30651-30656.

23. Kuida K, Zheng TS, Na S, Kuan C-Y, Yang D, Karasuyama H et al. Decreased apoptosis in the brain and premature lethality in CPP32-deficient mice. Nature 1996; 384: 368-372. 
24. O/'Donnell MA, Perez-Jimenez E, Oberst A, $\mathrm{Ng} \mathrm{A}$, Massoumi R, Xavier R et al. Caspase 8 inhibits programmed necrosis by processing CYLD. Nat Cell Biol 2011; 13: 1437-1442.

25. Gunther C, Martini E, Wittkopf N, Amann K, Weigmann B, Neumann H et al. Caspase-8 regulates TNF-alpha-induced epithelial necroptosis and terminal ileitis. Nature 2011; 477: 335-339.

26. Bohgaki T, Mozo J, Salmena L, Matysiak-Zablocki E, Bohgaki M, Sanchez 0 et al. Caspase-8 inactivation in T cells increases necroptosis and suppresses autoimmunity in Bim-/- mice. J Cell Biol 2011; 195: 277-291.

27. Vandenabeele P, Galluzzi L, Vanden Berghe T, Kroemer G. Molecular mechanisms of necroptosis: an ordered cellular explosion. Nat Rev Mol Cell Biol 2010; 11: 700-714.

28. Chen W, Frank ME, Jin W, Wahl SM. TGF- $\beta$ released by apoptotic T cells contributes to an immunosuppressive milieu. Immunity 2001; 14: 715-725.

29. Ren G, Su J, Zhao X, Zhang L, Zhang J, Roberts Al et al. Apoptotic cells induce immunosuppression through dendritic cells: critical roles of IFN- $\gamma$ and nitric oxide. J Immunol 2008; 181: 3277-3284.

30. Voll RE, Herrmann M, Roth EA, Stach C, Kalden JR, Girkontaite I. Immunosuppressive effects of apoptotic cells. Nature 1997; 390: 350-351.

31. Martin SJ, Henry CM, Cullen SP. A perspective on mammalian caspases as positive and negative regulators of inflammation. Mol Cell 2012; 46: 387-397.

32. Martin Seamus J, Henry Conor M, Cullen Sean P. A perspective on mammalian caspases as positive and negative regulators of inflammation. Mol Cell 2012; 46: 387-397.

33. Kono H, Rock KL. How dying cells alert the immune system to danger. Nat Rev Immunol 2008; 8: 279-289.

34. Festjens N, Vanden Berghe T, Vandenabeele P. Necrosis, a well-orchestrated form of cell demise: signalling cascades, important mediators and concomitant immune response. Biochim Biophys Acta 2006; 1757: 1371-1387.

35. Santoro MF, Annand RR, Robertson MM, Peng Y-W, Brady MJ, Mankovich JA et al. Regulation of protein phosphatase $2 \mathrm{~A}$ activity by caspase-3 during apoptosis. J Biol Chem 1998; 273: 13119-13128.

36. Emoto $Y$, Manome $Y$, Meinhardt G, Kisaki H, Kharbanda S, Robertson M et al. Proteolytic activation of protein kinase $\mathrm{C}$ delta by an ICE-like protease in apoptotic cells. EMBO J 1995; 14: 6148-6156.

37. Zhao X, Wang D, Zhao Z, Xiao Y, Sengupta S, Zhang R et al. Caspase-3-dependent activation of calcium-independent phospholipase $A 2$ enhances cell migration in non-apoptotic ovarian cancer cells. J Biol Chem 2006; 281: 29357-29368.

38. Lauber K, Bohn E, Kröber SM, Xiao Y-J, Blumenthal SG, Lindemann RK et al. Apoptotic cells induce migration of phagocytes via caspase-3-mediated release of a lipid attraction signal. Cell 2003; 113: 717-730.

39. Miossec C, Dutilleul V, Fassy F, Diu-Hercend A. Evidence for CPP32 activation in the absence of apoptosis during T lymphocyte stimulation. J Biol Chem 1997; 272 : 13459-13462.

40. Fernando $P$, Brunette $S$, Megeney LA. Neural stem cell differentiation is dependent upon endogenous caspase 3 activity. FASEB J 2005; 19: 1671-1673.

41. Fernando P, Kelly JF, Balazsi K, Slack RS, Megeney LA. Caspase 3 activity is required for skeletal muscle differentiation. Proc Natl Acad Sci 2002; 99: 11025-11030.

42. Mogi M, Togari A. Activation of caspases is required for osteoblastic differentiation. J Biol Chem 2003; 278: 47477-47482.

43. Laplante P, Sirois I, Raymond MA, Kokta V, Beliveau A, Prat A et al. Caspase-3-mediated secretion of connective tissue growth factor by apoptotic endothelial cells promotes fibrosis. Cell Death Differ 2009; 17: 291-303.

44. Hochreiter-Hufford AE, Lee CS, Kinchen JM, Sokolowski JD, Arandjelovic S, Call JA et al. Phosphatidylserine receptor BAl1 and apoptotic cells as new promoters of myoblast fusion. Nature 2013; 497: 263-267.

45. Gulyaeva NV, Kudryashov IE, Kudryashova IV. Caspase activity is essential for long-term potentiation. J Neurosci Res 2003; 73: 853-864.

46. Li Z, Jo J, Jia JM, Lo SC, Whitcomb DJ, Jiao S et al. Caspase-3 activation via mitochondria is required for long-term depression and AMPA receptor internalization. Cell 2010; 141: 859-871.

47. Pellettieri J, Fitzgerald P, Watanabe S, Mancuso J, Green DR, Sánchez Alvarado A. Cell death and tissue remodeling in planarian regeneration. Dev Biol 2010; 338: 76-85.
48. Li W, Kale A, Baker NE. Oriented cell division as a response to cell death and cell competition. Curr Biol 2009; 19: 1821-1826.

49. Chera S, Ghila L, Dobretz K, Wenger Y, Bauer C, Buzgariu W et al. Apoptotic cells provide an unexpected source of Wnt3 signaling to drive hydra head regeneration. Dev Cell 2009; 17: 279-289.

50. Apte U, Thompson MD, Cui S, Liu B, Cieply B, Monga SP. Wnt/beta-catenin signaling mediates oval cell response in rodents. Hepatology 2008; 47: 288-295.

51. Sato N, Meijer L, Skaltsounis L, Greengard P, Brivanlou AH. Maintenance of pluripotency in human and mouse embryonic stem cells through activation of Wnt signaling by a pharmacological GSK-3-specific inhibitor. Nat Med 2004; 10: 55-63.

52. Behrens J, von Kries JP, Kuhl M, Bruhn L, Wedlich D, Grosschedl R et al. Functional interaction of [beta]-catenin with the transcription factor LEF-1. Nature 1996; 382: 638-642.

53. Wodarz A, Nusse R. Mechanisms of Wnt signaling in development. Annu Rev Cell Dev Biol 1998; $14: 59-88$.

54. Huang Q, Li F, Liu X, Li W, Shi W, Liu FF et al. Caspase 3-mediated stimulation of tumor cell repopulation during cancer radiotherapy. Nat Med 2011; 17: 860-866.

55. Castellone MD, Teramoto H, Williams BO, Druey KM, Gutkind JS. Prostaglandin E2 promotes colon cancer cell growth through a Gs-axin- $\beta$-catenin signaling axis. Science 2005; 310: 1504-1510.

56. Goessling W, North TE, Loewer S, Lord AM, Lee S, Stoick-Cooper CL et al. Genetic interaction of PGE2 and Wnt signaling regulates developmental specification of stem cells and regeneration. Cell 2009; 136: 1136-1147.

57. Li F, Huang Q, Chen J, Peng Y, Roop DR, Bedford JS et al. Apoptotic cells activate the "Phoenix Rising" pathway to promote wound healing and tissue regeneration. Sci Signal 2010; 3110: ra13.

58. Bonner C, Bacon S, Concannon CG, Rizvi SR, Baquie M, Farrelly AM et al. INS-1 cells undergoing caspase-dependent apoptosis enhance the regenerative capacity of neighboring cells. Diabetes 2010; 59: 2799-2808.

59. Walker D. Wound healing: Phoenix rising. Nat Rev Mol Cell Biol 2010; 11: 232-233.

60. Hanahan D, Weinberg Robert A. Hallmarks of cancer: the next generation. Cell 2011; 144: 646-674.

61. Withers HR, Maciejewski B, Taylor JM, Hliniak A. Accelerated repopulation in head and neck cancer. Front Radiat Ther Oncol 1988; 22: 105-110.

62. El Sharouni SY, Kal HB, Battermann JJ. Accelerated regrowth of non-small-cell lung tumours after induction chemotherapy. Br J Cancer 2003; 89: 2184-2189.

63. Yamanaka N, Harabuchi $Y$, Kataura A. The prognostic value of Ki-67 antigen in non-Hodgkin lymphoma of Waldeyer ring and the nasal cavity. Cancer 1992; 70: 2342-2349.

64. Stuart-Harris R, Caldas C, Pinder SE, Pharoah P. Proliferation markers and survival in early breast cancer: a systematic review and meta-analysis of 85 studies in 32,825 patients. Breast 2008; 17: 323-334.

65. Todaro M, Alea MP, Di Stefano AB, Cammareri P, Vermeulen L, lovino $F$ et al. Colon cancer stem cells dictate tumor growth and resist cell death by production of interleukin-4. Cell Stem Cell 2007; 1: 389-402.

66. Ma S, Lee TK, Zheng BJ, Chan KW, Guan XY. CD133 + HCC cancer stem cells confer chemoresistance by preferential expression of the Akt/PKB survival pathway. Oncogene 2007; 27: 1749-1758.

67. Kroemer G, Reed JC. Mitochondrial control of cell death. Nat Med 2000; 6: 513-519.

68. Green DR, Kroemer G. The pathophysiology of mitochondrial cell death. Science 2004; 305: 626-629.

69. Kim KW, Moretti L, Lu B. M867, a novel selective inhibitor of caspase-3 enhances cell death and extends tumor growth delay in irradiated lung cancer models. PLOS One 2008; 3: e2275.

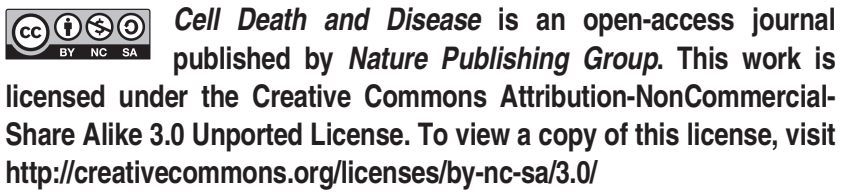

